\title{
Clinical practice as research for a rare condition: systematic research review of qualitative research exploring patients' experiences of penile cancer
}

\author{
Peter Branney ${ }^{1}$, Gary Raine ${ }^{2}$, Karl Witty ${ }^{2}$, Debbie Braybrook ${ }^{2}$, Kate Bullen ${ }^{3}$, Alan White ${ }^{2}$, Ian \\ Eardley ${ }^{4}$
}

1. School of Social, Psychological \& Communication Sciences, Leeds Metropolitan University, U.K. 2. Centre for Men's Health, Leeds Metropolitan University, U.K. 3. Psychology Department, Aberystwyth University, U.K. 4. Pyrah Department of Urology, St. James University Hospital, U.K.

Correspondence: Peter Branney. Address: School of Social, Psychological \& Communication Sciences, Leeds Metropolitan University, LS1 3HE, U.K. Email: p.branney@leedsmet.ac.uk

Received: June 5, 2013

DOI : $10.5430 /$ cns.v1n3p70
Accepted: July 23, 2013

URL: http://dx.doi.org/10.5430/cns.v1n3p70
Online Published: July 29, 2013

\section{Abstract}

Background: Penile cancer is a rare but destructive malignancy. The aim of this study was to identify published qualitative research exploring patients' experiences of being diagnosed and treated for penile cancer. As only one study met our inclusion criteria and yet there were five borderline studies, a secondary aim that emerged was to discuss those studies to see what, if anything, we could learn.

Methods: We searched ASSIA, CINAHL, EMBASE, PUBMED/MEDLINE, PsycINFO \& Web of Science and found 313 papers published since 1990. Two reviewers independently selected 17 papers for potential inclusion using titles and abstracts, which were obtained and independently assessed. A synthesis was not possible as only one study met our inclusion criteria. Five borderline studies, covering 4 countries, invited closer inspection because they are often reported in guidelines on penile cancer.

Results: The 5 borderline studies reported using a mixed methods design combining a psychometric measure with interviews. Unfortunately, none of these studies reported the method or process used for analysing qualitative data or for integrating the interview and psychometric findings, making it difficult to understand the interview element of their research.

Conclusions: If we are to understand and improve the long-term consequences of treatment for penile cancer, qualitative studies of patients' experiences need to be conducted with high quality analysis and reporting. While pen-and-paper questionnaires may take up little of the time of clinicians conducting research about rare conditions, time could be better used by using methodologies that explore patients experiences.

\section{Key words}

Systematic research review, Qualitative research, Penile cancer, Penis, Quality of life 


\section{I ntroduction}

Penile cancer is rare in western populations, with world standardised rates ranging from 0.5 to 1.6 new registrations annually per 100,000 men ${ }^{[1]}$. Although it has a low incidence rate, penile cancer is a destructive disease. When treating the primary tumour, the standard of care is to provide a cure while maintaining the sexual and urinary function of the penis (ibid.). Surgical excision of the primary tumour (and a margin of normal penile tissue) is the main form of treatment with chemotherapy and radiotherapy restricted to adjuvant use or palliative treatment of extensive disease. Depending on the size and position of the primary tumour, treatment may be limited to the surface of the glans (glans resurfacing), may require removal of a small section or the whole glans (glans resection and glansectomy, respectively), or may necessitate partial or total amputation of the penis (penectomy). Surgery is however generally uncomplicated and most patients recover good physical health with, for example, over $80 \%$ of those with early stage disease surviving longer than 5 years ${ }^{[2]}$. Consequently, patients have to live with the consequences of treatment for a long time. Understanding patients' experiences of penile cancer, particularly post-treatment, is important in order to improve treatment and support ${ }^{[3]}$.

Surgical treatment can result in great change to the form and function of the penis ${ }^{[3,4]}$ and there is some evidence to suggest that this in turn has an impact of self-image and mental well-being ${ }^{[4]}$. Nevertheless, research exploring the impact of the diagnosis and treatment of penile cancer is limited in scope, depth and quality ${ }^{[4]}$, drawing primarily upon psychometric measures to examine psychological well-being, quality of life and sexual function. Some men, for example, report no sexual function and yet have high sexual satisfaction. While we may hypothesise that it is possible to maintain an intimate and satisfactory sexual life without sexual function in the penis, we need to use research designs that are able to investigate the depth and breadth of experiences these men have after diagnosis and treatment.

Qualitative methods are widely accepted as the best way to explore patients' experiences ${ }^{[3]}$. In particular, semi-structured qualitative approaches allow us to ask research questions in ways that give participants the freedom to relate the unique aspects of their cancer journey. After building up a collection of "such stories", qualitative analyses can be utilised to find the common "themes" across individual patients' experiences and to construct a model through which we can understand such experiences ${ }^{[5]}$. The next level of such understanding is to examine multiple studies. Qualitative synthesis is a way of systematically searching the literature and then synthesising the findings across studies ${ }^{[6]}$. While quantitative designs have already been systematically reviewed ${ }^{[4]}$ and have the potential to provide generalisability, qualitative studies would provide the detail through which we could conceptualise the phenomena in question.

We conducted a systematic review of qualitative research about penile cancer and only one paper met our inclusion criteria and therefore a synthesis was unnecessary. However, there were five borderline studies that despite failing to meet inclusion criteria invite further scrutiny. In each of the studies, data was collected using a psychometric measure during a clinical appointment. While self-completion pen-and-paper questionnaires may appear to be quick and easy for the clinician, we would argue that when researching rare conditions, clinical time could be better employed. In this paper, we report the systematic search process and discuss the borderline papers to highlight what we can learn about using clinical practice to explore a rare condition such as penile cancer.

\section{The Review}

\subsection{Aim}

The aim of this study was to identify published qualitative research exploring patients' experiences of being diagnosed and treated for penile cancer. As only one study met our inclusion criteria and yet there were five borderline studies, a secondary aim that emerged from the research process was to discuss those studies to see what, if anything, we could learn. 


\subsection{Design}

The study used a systematic research review design to identify qualitative research exploring patients' experiences of the diagnosis and treatment of penile cancer. Had more than one study met our inclusion criteria, we would have synthesised the data using thematic coding ${ }^{[7]}$, identifying first-order constructs, creating a matrix of second-order constructs before completing the process with the higher-order themes about patients' experiences.

\subsection{Search methods}

To identify pertinent studies, we (a) conducted an electronic search of bibliographic databases, (b) consulted with experts and (c) reviewed the reference lists from articles that fulfilled our eligibility criteria. We searched ASSIA, CINAHL, EMBASE, PUBMED/MEDLINE, PsycINFO and Web of Science from 1990 to 2012. We initially tried searching for publications containing both a condition (penile cancer, etc.; see Table 1) and a methodology (qualitative, etc.) term in the citation record but this search strategy was too imprecise, providing tens of thousands of results. Subsequently, we added in a requirement that the citation also include a term linked to patients' experiences (quality of life, etc.)

\subsubsection{I nclusion criteria}

We wanted to include as wide a range of studies as possible and therefore included any publication from 1990 to 2012 reporting a study that used a qualitative method. In terms of methods, we included any mode of qualitative data collection (interview, focus group, etc) or analysis (grounded theory, thematic analysis, etc). We also included mixed-methods studies where a qualitative element was included within the design. The study had to include patients with penile cancer in the sample, although it did not have to focus solely on penile cancer patients.

\subsubsection{Exclusion criteria}

We excluded studies where it was impossible to disentangle the results of patients with penile cancer from the rest of the sample. This meant that the final studies considered were those that focused solely on penile cancer because research into multiple cancers did not separate qualitative findings by cancer type. While we were interested in the experiences of patients who had undergone surgery to their penis, we excluded studies about penile surgery not due to cancer, such as after a road traffic incident, because penile cancer is unique in practical (potential for the cancer to recur) and social (the meaning of cancer) terms. We also excluded reports of health professionals' experiences and narrative studies that only reported a patient's 'story' (without explaining the methodology employed).

\section{Results}

\subsection{Search outcome}

Including duplicates between bibliographic databases, 313 papers were identified and at least two researchers (PB, GR, KW, DB) independently reviewed the title and abstract for each (see Figure 1). Of these, 17 were considered potentially relevant and full copies obtained and again reviewed by at least two (PB, GR, KW, DB) researchers independently.

Only one Welsh study by Bullen et al., reported across three publications ${ }^{[8-10]}$, met our inclusion criteria and therefore a synthesis was impossible. There were 5 borderline studies (across 8 publications ${ }^{[11-18]}$ ) from 4 countries (see Table 1). Each borderline study combined interviews with psychometric measures, and such research could potentially be included in a qualitative synthesis. Unfortunately, the studies had to be excluded because they failed to report how they analysed the interview data, or to report the data in such a way that they could be distinguished from the quantitative findings. However, these 5 studies are drawn upon by European Association of Urology (EAU) guidelines for penile cancer ${ }^{[19]}$, particularly in relation to quality of life, and therefore they did invite further scrutiny in order to establish the way in which the interview method was actually used. 


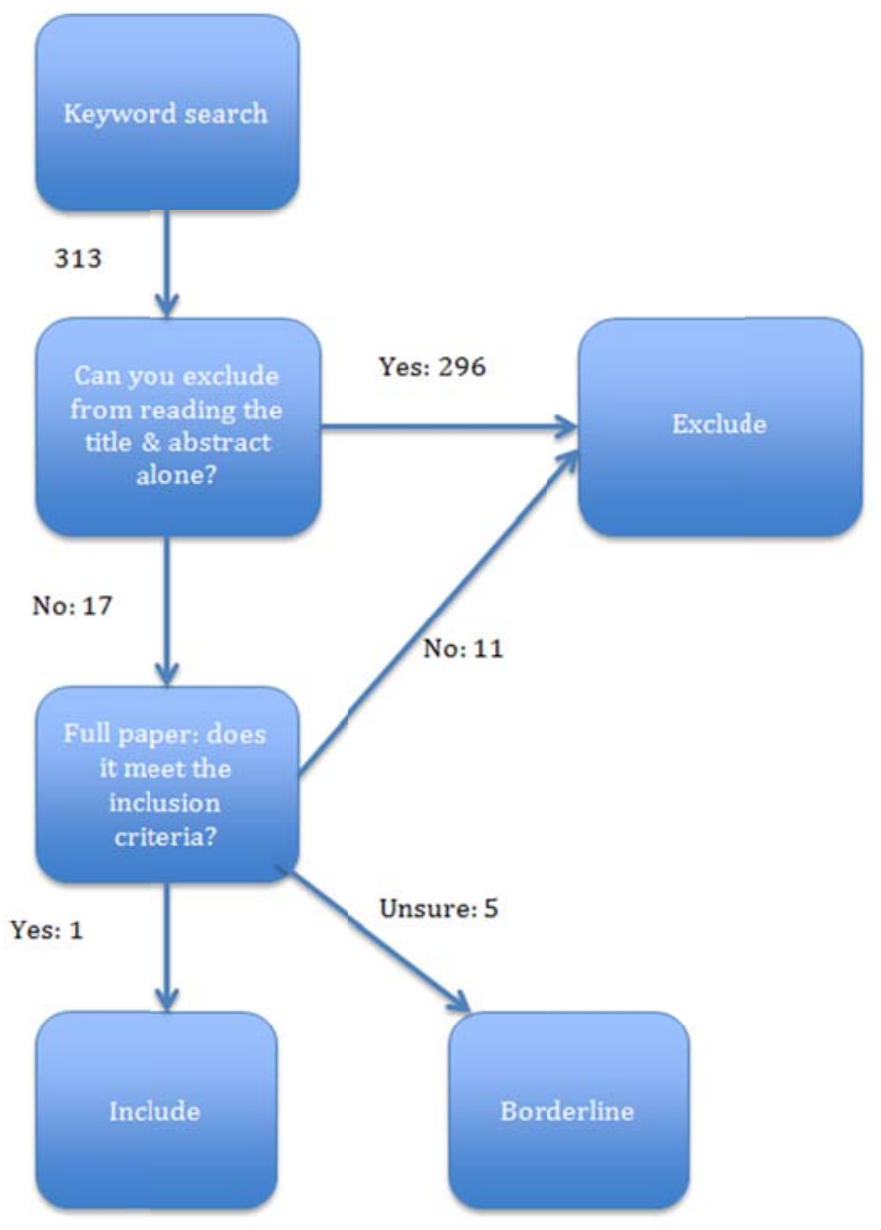

Figure 1. Search process

Table 1. Search terms

\section{Pubmed, CINAHL, PSYINFO, Assia \& web of science}

\#1 AND \#2 AND \#3

\#1 penile cancer OR penile carcinoma OR penile neoplasm OR (cancer AND penis) OR (carcinoma AND penis) OR (neoplasm AND penis)

\#2 quality of life OR self image OR body image OR masculinity OR experience* OR impact* OR wellbeing OR well-being OR well being OR satisfaction OR sexual function OR sexual dysfunction

\#3 interview* OR focus group* OR discussion group* OR case stud* OR observation OR mixed method* OR qualitative OR ethnograph* OR phenomenolog* OR thematic OR narrative OR grounded theory

\section{EMBASE:}

1 (penile cancer or penile carcinoma or penile neoplasm or (cancer and penis) or (carcinoma and penis) or (neoplasm and penis)).mp. [mp=title, abstract, subject headings, heading word, original title]

2 (quality of life or self image or body image or masculinity or experience\$ or impact\$ or wellbeing or well-being or well being or satisfaction or sexual function or sexual dysfunction).mp. [mp=title, abstract, subject headings, heading word, original title] 3 (interview\$ or focus group\$ or discussion group\$ or case study\$ or observation or mixed method\$ or qualitative or ethnograph\$ or phenomenolog\$ or thematic or narrative or grounded theory).mp. [mp=title, abstract, subject headings, heading word, original title] 41 and 2 and 3

Note. The * and \$ signs are truncation symbols. They allow alternative endings of terms to be identified. For example, searching cancer* will find cancer, cancers, cancerous, etc. 


\subsection{Borderline studies}

That urology guidelines for penile cancer cite five studies (the "borderline studies", see Table 2) that failed to meet our criteria for qualitative research of patients' experiences of being diagnosed and treated for penile cancer invites further discussion. In the most recent of two Brazilian studies ${ }^{[11]}$, the interview would be better termed a "clinical interview" because it was used to measure the penile shaft and assess complications post-surgery. In a Swedish study ${ }^{[12,13]}$, they conduct "structured interviews" where they deliver a questionnaire to the participant verbally. In an Italian study ${ }^{[14]}$, the interview reported was with a physician whose role appeared to be to answer questions about the study and/or explain any of the items in the psychometric measures with which the participant had difficulties. In a Norwegian study ${ }^{[16,17]}$, the researchers took a psychometric measure for testicular cancer and adapted it for use as a structured interview about penile cancer. In the earliest Brazilian study ${ }^{[18]}$, the interview was used to "evaluate" the patients. In this study, the method of data analysis is absent from the publications, but it appears that content analysis may have been used to examine the data.

Table 2. Borderline studies

\begin{tabular}{|c|c|c|c|}
\hline First Author & Country & Design & Our Interpretation of Method \\
\hline D’Ancona & Brazil & $\begin{array}{l}\text { Semi-structured interview with } \\
\text { psychometric measure }\end{array}$ & $\begin{array}{l}\text { Interview used to ‘evaluate’ participants. May have } \\
\text { used content analysis }\end{array}$ \\
\hline Ficarra & Italy & $\begin{array}{l}\text { Interview with psychometric } \\
\text { measure }\end{array}$ & $\begin{array}{l}\text { Interview used to explain study and describe items } \\
\text { on psychometric measure }\end{array}$ \\
\hline Romero & Brazil & $\begin{array}{l}\text { Personal interview \& } \\
\text { examination with psychometric } \\
\text { measure }\end{array}$ & Clinical interview used to examine penis \\
\hline Opjordsmoen & Norway & $\begin{array}{l}\text { Semi-structured interview with } \\
\text { psychometric measure }\end{array}$ & $\begin{array}{l}\text { Structured interview to administer psychometric } \\
\text { measure }\end{array}$ \\
\hline Windahl & Sweden & Face-to-face structured interview & $\begin{array}{l}\text { Structured interview to verbally administer } \\
\text { psychometric measure }\end{array}$ \\
\hline
\end{tabular}

While these five borderline studies may appear to combine an interview with psychometric measures, a careful reading seems to suggest that all but one are using interviews merely as a mode of administering questionnaires. There are two possible explanations. First, the researchers reporting the study have misrepresented their research as including a qualitative element. Any form of administering psychometric measures, whether by interview or by post, for example, should not be reported as a separate methodology. Second, the studies may have failed to report the analysis of their qualitative data, omitted to present their findings in a way that it can be distinguished from the quantitative results, or did not explain how they integrated the interview data with the results from the psychometric measures. In all five studies, it is possible that the interviews may have been used to help the researchers to interpret their findings. However, without adequate reporting, it is difficult to understand fully the interview element of these studies.

\section{Conclusion}

Penile cancer is a rare condition in the Western hemisphere that we would argue is potentially embarrassing and difficult for individuals to discuss. Thus, it is unsurprising that we found only one qualitative study exploring penile cancer. While we found five additional studies from across the globe that reported utilising interviews, we were unable to include them because of a lack of information on the methods used. Each study was a missed opportunity to gather and analyse qualitative data that could have helped to explore patients' experiences in detail.

The failure of penile cancer research to use and report qualitative methods to help explore patients' experiences is all the more disappointing given that it is a uncommon cancer in the West. Most rare conditions struggle to recruit sufficient participants to conduct research. In such instances, researchers might turn to online, email and/or postal questionnaires because the potential to recruit participants is much greater than with qualitative designs. Each of the five borderline 
studies, however, actually met with their participants one-to-one and therefore a qualitative study would have been not only possible but preferable.

The "quality of life" section in the EAU guidelines on penile cancer published between 2001-2009 only drew on three studies. In the 2001 guidelines ${ }^{[19]}$, no studies are cited even though at least three were available. In $2004{ }^{[20]}$, the Italian study ${ }^{[14]}$ is cited and in $2009^{[1]}$ the Swedish and second Brazilian studies ${ }^{[11,13]}$ are cited although the Italian study is omitted. Such inconsistences and the limited number of studies used in the guidelines could be viewed as an indication that more good quality, in depth data are required. Had the studies conducted previously made better use of qualitative methods, we would have an international understanding of patients' experiences to add to such guidelines.

The Welsh study that met our inclusion criteria ${ }^{[8-10]}$ provides an example of how we could explore quality of life after treatment for penile cancer; one-on-one semi-structured interviews guided by 6-8 questions, which encourage the participant to talk about their experiences. Nevertheless, there are a wide range of qualitative data collection and analytic methods available ${ }^{[21]}$, which often draw upon unique ways of thinking about and exploring the world. While medical science has long been associated with quantitative approaches, this does not necessarily mean it is incommensurate with qualitative research paradigms ${ }^{[21]}$. Qualitative methods have much to offer research in the medical sciences, particularly where there is currently little known about an issue. Furthermore, qualitative research is a specialist activity and should not be left to the novice ${ }^{[5]}$. We would recommend that experienced qualitative researchers are employed early on in the design of a study, so that they can provide expertise about the methods appropriate to the research question.

The authors experience has shown that recruiting for qualitative studies on patients' experiences of penile cancer can be a difficult process, and one requiring a significant amount of time and effort. While the pen and paper questionnaires used in the borderline studies may have required little of the clinicians time, we would argue that time is much better spent producing research that tells us something useful about patients' experiences. One potentially valuable step would be to bring clinicians, patients and researchers together in a research network. This would not only help to facilitate study recruitment but would be able to combine expertise and develop a portfolio of research that builds our understanding of patients' experiences.

\section{Funding statement}

This paper presents independent research commissioned by the National Institute for Health Research (NIHR) under its Research for Patient Benefit (RfPB) Programme (Grant Reference Number PB-PG-0808-17158). The views expressed are those of the author(s) and not necessarily those of the NHS, the NIHR or the Department of Health.

\section{Declarations of interest}

Ian Eardley is a consultant and speaker for Bayer, Lilly, and the other authors have nothing to disclose.

\section{References}

[1] Pizzocaro G, Algaba F, Horenblas S, Solsona E, Tana S, Van Der Poel H, et al. EAU Penile Cancer Guidelines 2009. European Urology. 2010; 57(6):1002-12. PMid:20163910 http://dx.doi.org/10.1016/j.eururo.2010.01.039

[2] Pizzocaro G, Algaba F, Solsona E, Tana S, Van Der Poel H, Watkin N, et al. Guidelines on penile cancer. Arnhem, The Netherlands: European Association of Urology; 2010.

[3] Branney P, Witty K, Eardley I. Patients' Experiences of Penile Cancer. European Urology. 2011; 59(6):959-61. PMid:21377264 http://dx.doi.org/10.1016/j.eururo.2011.02.009

[4] Maddineni S, Lau M, Sangar V. Identifying the needs of penile cancer sufferers: A systematic review of the quality of life, psychosexual and psychosocial literature in penile cancer. BMC Urology. 2009; 9(1):8.

PMid:19664235 http://dx.doi.org/10.1186/1471-2490-9-8

[5] Pope C, Ziebland S, Mays N. Qualitative research in health care: analysing qualitative data. BMJ. 2000;320(7227):114-6. PMid:10625273 http://dx.doi.org/10.1136/bmj.320.7227.114 
[6] Pope C, Mays N, Popay J. Synthesizing qualitative and quantitative health evidence: a guide to methods. Maidenhead, UK: McGraw Hill Open University Press; 2007.

[7] Bennion AE, Shaw RL, Gibson JM. What do we know about the experience of age related macular degeneration? A systematic review and meta-synthesis of qualitative research. Social Science \& Medicine. 2012 Sep; 75(6):976-85. PMid:22709445 http://dx.doi.org/10.1016/j.socscimed.2012.04.023

[8] Bullen K, Edwards S, Marke V, Mathews S. Psychological and quality of life outcomes in the treatment of men with penile cancer. Aberystwyth, Wales: Aberystwyth University; 2008.

[9] Bullen K, Edwards S, Marke V, Matthews S. Looking past the obvious: experiences of altered masculinity in penile cancer. Psycho-Oncology. 2010; 19(9): 933-940. PMid:19862691 http://dx.doi.org/10.1002/pon.1642

[10] Bullen K, Matthews S, Edwards S, Marke V. Exploring men's experiences of penile cancer to improve rehabilitation. Nursing Times. 2009; 105(12): 20-4. PMid:19363931

[11] Romero FR, Richter Pereira dos Santos Romero K, de Mattos MAE, Camargo Garcia CR, de Carvalho Fernandes R, Cardenuto Perez MD. Sexual function after partial penectomy for penile cancer. Urology. 2005; 66(6):1292-5. PMid:16360459 http://dx.doi.org/10.1016/j.urology.2005.06.081

[12] Windahl T, Skeppner E, Andersson SO, Fugl-Meyer KS. Sexual function and satisfaction in men after laser treatment for penile carcinoma. Journal of Urology. 2004 Aug; 172(2):648-51. PMid:15247753 http://dx.doi.org/10.1097/01.ju.0000132891.68094.87

[13] Skeppner E, Windahl T, Andersson S-O, Fugl-Meyer KS. Treatment-Seeking, Aspects of Sexual Activity and Life Satisfaction in Men with Laser-Treated Penile Carcinoma. European Urology. 2008; 54(3):631-9. PMid:18788122 http://dx.doi.org/10.1016/j.eururo.2007.10.028

[14] Ficarra V, Mofferdin A, D'Amico A, Zanon G, Schiavone D, Malossini G, et al. Quality of life in patients who have undergone surgical or radiotherapeutic treatment for squamous cancer of the penis. Progres En Urologie. 1999 Sep; 9(4):715-20. PMid:10555226

[15] Ficarra V, Righetti R, D'Amico A, Pilloni S, Balzarro M, Schiavone D, et al. General state of health and psychological well-being in patients after surgery for urological malignant neoplasms. Urologia Internationalis. 2000; 65:130-4. PMid:11054029 http://dx.doi.org/10.1159/000064857

[16] Opjordsmoen S, Fossa SD. Quality of life in patients treated for penile carcinoma: a follow-up study. British Journal of Urology. 1994;74:652-7. http://dx.doi.org/10.1111/j.1464-410X.1994.tb09200.x

[17] Opjordsmoen S, Waehre H, Aass N, Fossa SD. Sexuality in patients treated for penile cancer: patients' experience and doctors' judgement. British Journal of Urology. 1994; 73(5):554-60. PMid:8012779 http://dx.doi.org/10.1111/j.1464-410X.1994.tb07643.x

[18] D'Ancona CA, Botega NJ, De Moraes C, Lavoura NS, Jr., Santos JK, Rodrigues Netto N, Jr. Quality of life after partial penectomy for penile carcinoma. Urology. 1997 Oct; 50(4):593-6. http://dx.doi.org/10.1016/S0090-4295(97)00309-9

[19] Algaba F, Horenblas S, Pizzocaro-Luigi Piva G, Solsona E, Windahl T. EAU Guidelines on Penile Cancer. European Urology. 2002; 42(3):199-203. http://dx.doi.org/10.1016/S0302-2838(02)00308-1

[20] Solsona E, Algaba F, Horenblas S, Pizzocaro G, Windahl T. EAU Guidelines on Penile Cancer. European Urology. 2004; 46(1):1-8. PMid:15183542 http://dx.doi.org/10.1016/j.eururo.2004.03.007

[21] Madill A, Gough B. Qualitative research and its place in psychological science. Psychological Methods. 2008 ; $13(3): 254-71$. PMid:18778154 http://dx.doi.org/10.1037/a0013220 